\title{
A internacionalidade da literatura alemã
}

[German literature worldwide]

http://dx.doi.org/10.11606/1982-88372237408

Paulo Astor Soethe ${ }^{1}$

Resenha de: RICHTER, Sandra. Eine Weltgeschichte der deutschsprachigen Literatur. Munique: C. Bertelsmann, 2017. 728 p.

Para quem se dedica no ambiente acadêmico à pesquisa e docência de uma literatura estrangeira, logo se evidencia que a internacionalidade é elemento constitutivo de muitas obras e autores que se impõem, pouco a pouco, como seu objeto de trabalho e reflexão. As referências nacionais historicamente determinantes da delimitação disciplinar de sua área tornam-se porosas, e os ganhos cognitivos que nascem da valorização dessa porosidade acabam justamente se revelando como fonte de contribuição efetiva à atividade científica, tanto sob o ponto de vista da reflexão teórica quanto sob o parâmetro da revelação de novos dados, informações e conteúdos filológicos, histórico-literários e hermenêuticos. Na Germanística brasileira é inevitável dedicar atenção a um autor como Stefan Zweig, cuja biografia e produção vinculam-no diretamente ao Brasil. Da mesma forma, é incontornável dedicar atenção às relações de escritores brasileiros com a cena de língua alemã: edições originais de livros de Gonçalves Dias, como os Cantos ou Os Timbiras, por exemplo, foram publicadas em Leipzig, cidade frequentada pelo poeta; alguns dos poemas mais conhecidos do romântico brasileiro contêm epígrafes em alemão (na "Canção do exílio", um texto de Goethe, em "Se se morre de amor", um texto de Schiller); e o poeta mesmo foi tradutor excepcional de obras de língua alemã ao português, como A noiva de Messina. O espaço transareal que se cria em um par como o brasileiro-alemão tem caráter bem menos episódico e anedótico que se possa supor, oferece para a pesquisa muito material e documentação inexplorados - e mesmo assim

\footnotetext{
${ }^{1}$ Universidade Federal do Paraná, Rua General Carneiro, 460, Curitiba, 80060-000, PR, Brasil. E-mail: paulosoethe@me.com. ORCID: 0000-0002-9810-0530
}

\section{(cc) BY-NC}

Pandaemonium, São Paulo, v. 22, n. 37, mai.-ago. 2019, p. 408-414 
revela somente um recorte, ainda bastante parcial, das dinâmicas multipolares que de fato caracterizam a produção e circulação literárias, em qualquer contexto.

Daí o enorme mérito e interesse (também para o público brasileiro em geral) do trabalho de Sandra Richter em seu estudo Eine Weltgeschichte der deutschsprachigen Literatur (Uma história mundial da literatura de língua alemã), lançado no final de 2017: como germanista alemã, a autora fez jus ao trânsito internacional em sua atuação acadêmica (com estações na Inglaterra e França, Estados Unidos e China), dedicando-se a desenvolvimentos teóricos e práticos em consonância com a desnacionalização dos Estudos Literários, por certo mais apropriados à complexidade e liberdade dos processos de produção, recepção e circulação literária. Mesmo mergulhada em um ambiente acadêmico "nacional", como docente universitária na Alemanha, tratou de elucidar processos, obras e autores da literatura de língua alemã sob o viés da participação desses textos na assim chamada república mundial das Letras.

Em considerações sobre a historiografia literária global no primeiro capítulo de seu livro, um "Prólogo", Sandra Richter, titular de Literatura Alemã das Idades Moderna e Contemporânea (Neuere Deutsche Literatur) na Universidade de Stuttgart, apresenta fundamentos e métodos para o estudo que desenvolverá ao longo de outras 600 páginas de texto e notas, acrescidas ainda de ampla bibliografia e índice remissivo. Richter, mãe de duas filhas em idade escolar, às quais dedica seu livro, e até então, em 2008, a mulher mais jovem a assumir uma cátedra em universidades alemãs, serve-se de estilo direto, elegante e acessível para apresentar ao leitor casos exemplares de obras e autores que se tornaram "artigo de exportação" e que, mais que isso, retroalimentaram o ambiente de produção literária na Europa de língua alemã, de 1450 até a atualidade.

O capítulo seguinte do livro, sobre o período de 1450 a 1700, inaugura a apresentação de uma série de casos exemplares, que se entretecem para compor o painel assumida e necessariamente incompleto de uma história literária mundial. O que o estudo propõe, afinal, é também uma abordagem da literatura de língua alemã. Com informações básicas sobre a obra e seu contexto de produção e publicação, o que torna o livro bastante acessível também para um público não especializado, a autora dedica-se de início a um dos primeiros best-sellers europeus, a narrativa satírica de Sebastian Brant Das Narrenschiff (1494; traduzida em 2010 no Brasil por Karin Volobuef com o título A nau dos insensatos). De maneira leve e espirituosa, Richter acompanha a obra de Brant em várias estações de sua recepção, até alcançar o ponto mais distante no itinerário geográfico e temporal a ser percorrido pelo leitor: "468 anos depois de Brant, zarpou uma

Pandaemonium, São Paulo, v. 22, n. 37, mai.-ago. 2019, p. 408-414 
próxima nau dos insensatos" (p. 41). Trata-se aqui de um eco literário e cinematográfico de Das Narrenschiff nos Estados Unidos (destinado à circulação mundial, portanto): primeiro com o romance de Katherine Anne Porter Ship of Fools (1962), e logo a seguir no filme homônimo, de 1965, dirigido por Stanley Kramer. O filme recebeu os óscares de melhor fotografia e melhor direção de arte (para filmes em preto e branco) em 1966, além de diversas indicações em outras categorias.

Ao abrir esse espectro de quase 500 anos entre publicação da obra alemã e sua repercussão nos meios da cultura de massa do outro lado do Atlântico, Sandra Richter delineia já no início de sua empreitada o espectro amplo de liberdade reflexiva (e às vezes associativa) que o estudo assume, legitimado pelas diversas reviravoltas epistemológicas e metodológicas (os diversos turns) por que passaram os Estudos Literários em décadas recentes. De algum modo, no entanto, esse exemplo inicial também assume o caráter de caso-limite, já que é um dos poucos exemplos de referência cultural distante e relativamente solta, do ponto de vista filológico. Na sequência, sob regime bem mais característico do estudo todo, Richter prossegue com a descrição minuciosa do trajeto de novos textos, motivos e personagens em ambientes externos ao espaço de língua alemã, sob a indicação de agentes literários e culturais, fontes históricas e bibliográficas, e remissão a ampla bibliografia e documentação. É o que se dá, por exemplo, com a apresentação do romance Fortunatus (1509), seu protagonista e tema moral, revitalizado e testado em seus limites sob várias apropriações e recriações, desde o século XVI ao XIX.

No mesmo capítulo, dá-se ainda a primeira referência extensa ao Brasil, com o comentário sobre outro best-seller europeu: um subcapítulo todo é dedicado ao romance escrito pelo mercenário Hans Staden, que viajou duas vezes ao sudeste brasileiro, tendo sobrevivido em uma das viagens a nove meses de cativeiro impostos por índios tupinambás. Também aqui Sandra Richter documenta as diversas reimpressões, traduções e recriações da obra até a atualidade. A página 56 do livro, quase inteira, é tomada por reprodução da capa de edição recente da adaptação de Monteiro Lobato para o público infantil, As aventuras de Hans Staden, com ilustrações de Luiz Maia (Editora Globinho). A propósito, a produção gráfica do livro de Richter, com intertítulos em vermelho, diagramação agradável e rica gama de ilustrações, em geral bastante úteis e bem integradas ao texto, é outro aspecto positivo da publicação da editora C. Bertelsmann, destinada não apenas à comunidade acadêmica, como se disse. (Uma sessão de 15 páginas de gráficos e mapas ao final do livro, inclusive, procura dar noção, a partir de exemplos Pandaemonium, São Paulo, v. 22, n. 37, mai.-ago. 2019, p. 408-414 
pontuais, da difusão de obras de língua alemã no mundo, a partir de casos particulares, como o da obra de Franz Kafka.)

O capítulo 3 dedica-se ao período de 1680-1770, com destaque, por exemplo, à peça Nathan, o sábio (Nathan der Weise), de Gotthold Ephraim Lessing, obra chave do Iluminismo europeu, sobre o convívio entre as grandes religiões monoteístas. Por todas as tensões que caracterizam o Oriente Médio na atualidade, e sobretudo a partir do $11 \mathrm{de}$ Setembro, com o aguçamento de associações negativas ao Islã no Ocidente como um todo, aumentou muito a atenção a esse texto de Lessing. Daí tanto mais apropriado que o livro de Sandra Richter descreva a repercussão da peça na cena mundial, inclusive para constatar limitações da obra em sua efetiva circulação, tanto em Israel como no mundo árabe (onde o texto é praticamente desconhecido). Curioso, no estudo de Sandra Richter (p. 112), o relato sobre a encenação dessa peça em 1956 na Deutsche Bühne de Buenos Aires, Argentina, em meio às tensões que marcavam o convívio de grupos de língua alemã naquele país: judeus e nacionalistas alemães, em parte emigrados após a Segunda Guerra Mundial, aos quais o teatro deu ocasião rara de encontro sob um mesmo teto. Esse exemplo pontual, entre outros, revela quanto a documentação ainda inexplorada (periódicos, cartas, diários, registros da atividade cultural em língua alemã na América Latina, especialmente no teatro) pode mesmo contribuir, quando se trata de escrever uma história mundial da literatura de língua alemã. Pois se o exemplo é interessante e elucidativo daquele momento histórico, ele também ratifica, no entanto, certa limitação existente na associação entre presença alemã na América do Sul, de um lado, e decorrências da barbárie nacional-socialista, de outro. A associação esconde que esses tempos obscuros foram antecedidos por décadas de outro tipo de participação e interlocução de cidadãos de língua alemã no subcontinente, de coloração política diversa, não raro decididamente democrática.

Disso dá conta, no caso da América do Norte, boa parte do capítulo 4 do livro de Sandra Richter, dedicado ao período de 1770 a 1830. A fase é protagonizada, como não poderia deixar de ser, por Johann Wolfgang von Goethe, especialmente com Os sofrimentos do jovem Werther e Fausto. Entre diversos outros aspectos, o capítulo dedica longo trecho à repercussão da obra de Goethe junto aos transcendentalistas norteamericanos. O estudo descreve, nesse sentido, a circulação de textos de língua alemã nos Estados Unidos, em um ambiente então multilíngue, com ampla presença do alemão como idioma corrente na produção e debates culturais. Nesse mesmo capítulo, vale destacar um indício de quanto a maior atenção à presença da língua e literatura alemã no Pandaemonium, São Paulo, v. 22, n. 37, mai.-ago. 2019, p. 408-414 
contexto brasileiro podem render conhecimento acadêmico e científico não apenas à própria historiografia literária brasileira, mas também à cena internacional: o subcapítulo “Allemanismo brasileiro, um demônio homossexual e Manuel Antônio Álvares de Azevedo" (p. 188-191) dedica-se sobretudo a Macário, além de mencionar alguns de seus "sucessores" no diálogo literário brasileiro com Goethe, a saber Machado de Assis e Guimarães Rosa.

É de fato desejável, com base em trabalhos da Germanística brasileira já disponíveis, e na interface entre essa disciplina e os Estudos de Literatura Brasileira, que se aprofunde a pesquisa sobre a relação de autores brasileiros com a cena alemã. Que Álvares de Azevedo tenha mencionado muitos poetas de língua alemã em sua obra (às vezes de maneira pouco perceptível, referindo-se a Jean Paul como João Paulo Richter, por exemplo); ou que um autor alemão como Ludwig Uhland (hoje tão pouco conhecido no Brasil) tenha sido para Álvares de Azevedo talvez a referência poética mais importante; ou que o poeta brasileiro tenha aprendido alemão na infância, de modo a fazer constar como produção própria em sua Lira dos vinte anos uma tradução de poema de Heinrich Heine - nada disso parece estar presente no universo de referências dos estudos de sua obra no Brasil (tal como, mal comparando, é o caso da associação corrente entre os indianismos de José de Alencar e de François-René de Chateaubriand). Quando tais aspectos da obra de Álvares de Azevedo estiverem mais presentes em nossa historiografia, eles certamente se tornarão mais visíveis também em um estudo como o de Sandra Richter. A propósito muito do que seu livro menciona sobre o Brasil deve-se às estudantes brasileiras de Letras Alemão Taciane Murmel e Débora Raymann, que colaboraram com a autora.

O capítulo 5 (1830-1890) aprofunda, entre outros assuntos, mais uma vez a questão da presença alemã nos Estados Unidos. Na sequência, o capítulo 6 (1890-1930) dedica-se a autores alemães de grande repercussão internacional no contexto de globalização acelerada impulsionada pelo colonialismo, a industrialização, a difusão de informações pela imprensa e novos meios de comunicação, bem como pelo acontecimento da Primeira Grande Guerra e iminência da Segunda: Thomas Mann, Rainer Maria Rilke e Franz Kafka são aqui os protagonistas. De grande interesse é também o subcapítulo sobre a revista Der Sturm, uma das experiências mais sólidas de internacionalização literária envolvendo a cena de língua alemã, em época de consolidação das vanguardas e renovação da literatura no Ocidente de forma "coordenada", com debates globais e intensa circulação de ideias, posicionamentos, Pandaemonium, São Paulo, v. 22, n. 37, mai.-ago. 2019, p. 408-414 
produtos culturais e reações criativas por parte de escritores, críticos e intelectuais de procedências diversas.

No capítulo 7, dedicado aos anos 1930 a 1960, Sandra Richter confronta-se com o contexto de dispersão dos autores de língua alemã em situação de fuga e exílio. Aqui merece especial atenção o caso de Stefan Zweig, cuja relação trágica com o Brasil se revitaliza ao tornar-se objeto de história em quadrinhos e realização cinematográfica recentes, aos quais a autora dedica comentário relativamente extenso. Outros autores judeus de língua alemã como Rose Ausländer, Paul Celan e Elias Canetti e os respectivos contextos de produção e recepção internacional de suas obras recebem atenção especial da autora, com destaque para a importância que a tradução e o debate teórico sobre tradução assumem nesses casos. De outra parte, o estudo dedica-se à atuação de Thomas Mann como exilado alemão na América do Norte e um dos principais líderes mundiais no combate intelectual ao fascismo.

Os capítulos seguintes, 8 e 9, são dedicados respectivamente às literaturas da Alemanha cindida entre os blocos comunista e capitalista (1945-1989) e ao período desde a reunificação (a partir de 1989). No primeiro caso, Sandra Richter apresenta panoramas editoriais e, em particular, as editoras Aufbau, no Leste, e Suhrkamp, no Oeste, como agentes de internacionalização das cenas literárias de seus respectivos países, a RDA e a RFA, àquela época. Não ficam de fora, naturalmente, autores e circunstâncias dos demais países de língua alemã. No capítulo 8 , a autora tece comentários longos e elucidativos sobre autores de grande repercussão internacional, todos conhecidos também no Brasil: Heinrich Böll, Günter Grass, Hermann Hesse e Thomas Bernhard. No capítulo 9, Richter confere destaque a escritores que evidenciam, de dentro, a abertura da cena literária de língua alemã para o "outro como parte de si mesmo": Emine Özdamar e Feridun Zaimoglu, autores turco-alemães, e Yoko Tawada, poeta nipo-alemã, são alguns exemplos. Fenômeno alemão conhecido no Brasil em particular desde a publicação de EscreverEntreMundos, de Ottmar Ette (Curitiba, 2018, com tradução de Rosani Umbach, Dionei Mathias e Teruco Spengler), a experimentação com elementos inter- e translinguais na nova literatura multicultural de língua alemã encerra o panorama oferecido por Sandra Richter.

O "Epílogo" traz ainda, no entanto, as conclusões teóricas e sínteses a que a autora chega, cumprido seu périplo de muitos séculos e muitos milhares de quilômetros em torno do globo. São 25 teses sobre as qualidades formais, processos translativos, condicionantes de visibilidade e prestígio, assimetrias e acronias, consensos e extraterritorialidades que Pandaemonium, São Paulo, v. 22, n. 37, mai.-ago. 2019, p. 408-414 
SOETHE, P. - A internacionalidade da literatura alemã

marcam os fenômenos não raro conflituosos de constituição da cena literária internacional, da qual participam também os textos e autores de língua alemã. A tese final, de qualquer modo, destaca com otimismo o fato de que, ao contrário do que se parecia temer, há desde o fim do século XX cada vez mais traduções, publicações e - pode-se ter certa esperança - práticas mais intensas de leitura. Daí o livro encerrar-se com o aceno em direção a um desejável humanismo crítico, "que não expõe em via única valores universais, mas que se põe em busca de coisas em comum, em um mundo potencialmente vincado por cisões sempre maiores" (p. 481). Para Sandra Richter, "narrativas lidas de forma global, problemas planetários e a consciência quanto a insegurança do futuro podem gerar tais coisas em comum: eis a grande esperança" (idem).

Parece ser bom augúrio e vaticínio favorável à esperança que o livro expressa o fato de Sandra Richter - autora justamente de um livro como esse, mulher, mãe, pesquisadora precoce e excepcional em sua produção, perspectivação da história e prospecção de um futuro para a literatura de língua alemã - ter sido escolhida e nomeada a partir do início de 2019 diretora de uma das instituições mais importantes da cena literária alemã, o Deutsches Literaturarchiv (DLA, Arquivo Literário Alemão) na cidade de Marbach.

Seu livro merece recepção intensa e produtiva, também no Brasil, e não só pela cena ligada à literatura de língua alemã. Daí a conveniência e oportunidade de uma tradução brasileira, que se registra aqui como desiderato e recomendação. 